\title{
The beef breeding herd: options for using winter feed most productively
}

\author{
W.H. McMILLAN and D.G. MCCALL \\ Whatawhata Research Centre, MAF Technology, Private Bag 3089, Hamilton
}

\begin{abstract}
A spreadsheet model has been developed to allow a comparison of policies for beef breeding cows. The criterion for comparison is the $\mathrm{kg}$ of calf weaned perkg of winter feed requiredi.e. efficiency. The model allows adjustment in number of animals wintered so that all policies have the same winter feed requirement. Policies which favour higher efficiencies include: timing mean calving date at the end of the winter, using breeds of bull with high growth rate and high survival rate progeny, older rather than younger herd age structures. and wintering only pregnant heifers and cows after pregnancy diagnosis. The mos $\mathrm{t}$ scope for improving efficiency is in herd age structure while the least scope is in calving date. The analysis demonstrates that that the most efficient options are a combination of policies. The best combination is about $26 \%$ moreefficient than the worst combination. National beef herd statistics are required to assess the likely impact of changes on the industry.
\end{abstract}

Keywords beef cows, weaning weight, herd age structure, pregnancy diagnosis, feed requirements, time of calving, terminal sires

\section{Introduction}

In a seasonal pastoral system, one measure of efficiency inthebeefherdis theweightofcalfweanedperunitland required to feed them. To date, most published indicies of efficiency have been based on per head performance. For example, yearling heifer mating and dairy cross breeding cows have been advocated as a means of increasing per head performance (e.g. Morris 1982). Little consideration has previously been given to the additional feed requirements associated with these options. Our previous paper considered yearling heifer mating and dairy $\mathrm{x}$ beef breeding cows as policies for using winter feed efficiently (McMillan \& McCall 1991). In that paper we developed a spreadsheet model to compare the efficiency of beef breeding herds based on the weight of calf weaned per unit of winter feed requirement.
The purpose of this analysis is to use this model to compareotherpoliciesforusing winterfeedefficiently. These policies are time of calving, breed of bull, age at culling, and the wintering of non-pregnant cows after mating. We use the same index of efficiency as previously, namely total $\mathrm{kg}$ calf weaning weight per $\mathrm{kg}$ of winter feed required for the herd. The results from an Angus herd with first mating at 2 years of age are presented.

\section{Materials and methods}

\section{Estimated feed requirements}

The winter feed requirements are chosen to compare policies since the winter period is the most difficult period for matching feed requirements with feed supply on most properties. An arbitrary 120 day winter period is chosen. Winter feed requirements for pregnant and non pregnant heifers and cows, and for replacements are estimated as in ourprevious paper (McMillan \&McCall 1991). The mean feed requirements during the first month of lactation ( $\mathrm{kg} \mathrm{DM} / \mathrm{head} / \mathrm{day}$ ) are estimated to be 9.0 and 9.4 for 3-year-old heifers and adult cows respectively.

\section{Assumptions}

The mean of seven years per head performance data from the Whatawhata Research Centre Angus beef cow herd (McCall et al. 1987) is used to generate appropriate age structures and performance levels. The Base Angus Herd is assumed to be a herd with: 1. compulsory age culling at 10.5 years; 2 . first mating at 2 years of age; 3 . all non-pregnant cows culled after pregnancy diagnosis and before the start of the winter; 4 a minimum of yearlings wintered to maintain herd age structure and numbers; 5. only Angus bulls used as sires; 6 . all heifers and cows whichcalve but fail toweancalves retained for the following winter provided they are pregnant; 7 . weaning on a fixed date at a mean calf age of $\mathbf{5}$ months; 8. first mating for 6 weeks and subsequent mating for 8 weeks; and 9. mean calving date at the end of the winter. The efficiency of the Base Angus Herd is assumed to be 100. 


\section{Policy comparisons}

The analysis compares mean calving dates of either 15 or 30 days earlier and 15 days later (Late Calving) than assumed in the Base Herd. Data from Smeaton et $\boldsymbol{n l}$. (1986) are used to estimate the effects of time of calving on performance. We assume that pregnancy rates are unaffected by time of calving where cows are fed to a conmon live weight at calving. The effect of different breeds of bull (Baker $\boldsymbol{e t} \boldsymbol{a l}$. 1990) used for second and subsequent calving are compared. Compulsory culling at 4.5 years to 9.5 years is compared We assume that mean performance is the same in each age group from 4.5 years to 10.5 years of age. We investigate the effect of wintering non-pregnant cows and heifers, thus simulating a policy of no pregnancy diagnosis. Nonpregnant cows and heifers are assumed to eat the same as pregnant cows. Non-pregnant cows and heifers are culled after the end of the winter but prior to the next mating, essentially forming a finishing mob.

\section{Results}

Herds calving 30 days and 15 days early have efficiencies of 95 and 97 compared to 100 in the Base Herd (Table 1). The Late Calving herd has an efficiency of 98 . Fewer total animals are wintered and consequently fewer calves are weaned in earlier calving herds when compared with the Base Herd. However, the calves are heavier (because they are older) at weaning by $16 \%$ and $8 \%$ if calved 30 and 15 days earlier respectively. In contrast, more total animals are wintered and therefore more calves are weaned in the Late Calving herd but the calves are lighter (because they are younger) at weaning by about $7 \%$ compared to calves in the Base Herd.

Table 1 Relative number of cows and replacements wintered, calves weaned, mean calf weaning weight and efficiency when considered at the same total winter feed requirement.

\begin{tabular}{|c|c|c|c|c|c|c|}
\hline & $\begin{array}{l}\text { Base Early } \\
\text { herd calving } \\
\text { ( } 30 \text { days })\end{array}$ & $\begin{array}{l}\text { Early } \\
\text { calving } \\
\text { (15 days) }\end{array}$ & $\begin{array}{l}\text { Late } \\
\text { calving }\end{array}$ & $\begin{array}{l}\text { Best Y } \\
\text { breed } \\
\text { bull }\end{array}$ & $\begin{array}{l}\text { 'oungest } \\
\text { herd }\end{array}$ & $\begin{array}{c}\text { All Non } \\
\text { pregnants } \\
\text { wintered }\end{array}$ \\
\hline \multicolumn{7}{|c|}{ No. animals wintered } \\
\hline & 100 & 89 & 105 & 97 & 109 & 99 \\
\hline \multirow[t]{2}{*}{ No. calves } & weaned & & & & & \\
\hline & 100 & 91 & 106 & 98 & 69 & 92 \\
\hline \multicolumn{7}{|c|}{ Calf weight at weaning } \\
\hline & 116 & 108 & 93 & 113 & 98 & 100 \\
\hline \multicolumn{7}{|l|}{ Efficiency } \\
\hline & 100 & 97 & 98 & 110 & 66 & 92 \\
\hline
\end{tabular}

The most efficient bull breeds are the French and German Simmental and the Friesian (mean=109 vs 100 for Angus bull). In the middle group are the South Devon, Blonde D' Aquitaine, Swiss Simmental and the
Maine Anjou (mean=106) followed by the Hereford, Limousin, and Chianina (mean=103) breeds. The least efficient breeds of bull are the Austrian Simmental, Jersey, Angus and Charolais (mean=100). Breed of bull has a large influence on calf survival and consequently the number of calves weaned. The number of calves weaned ranges from 91 (Charolais) to 103 (Jersey) relative to 100 calves weaned in the Base Herd.

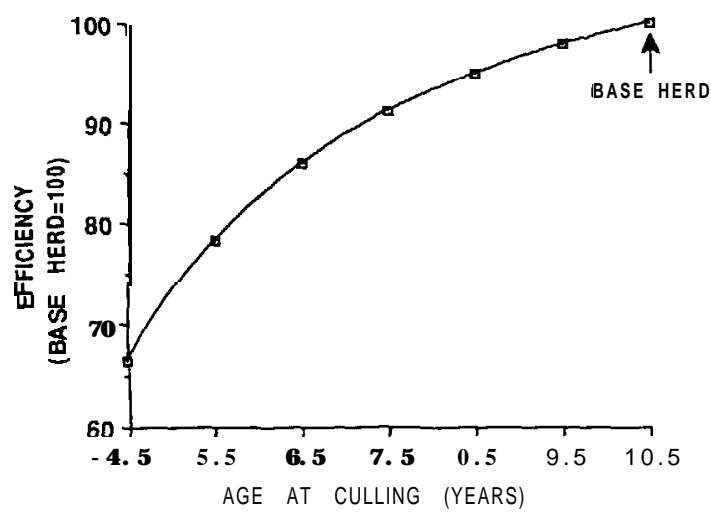

Figure 1 Efficiency of winter feed use in an Angus herd with compulsory culling between 4.5 and 10.5 years of age (Base Herd $=100$ ).

Age at compulsory culling is a significant source of variation in efficiency (Figure 1). Two key points are apparent. First, efficiency is lowest in the youngest herd. This result can be explained by the reduction in number of calves weaned which is a reflection of the increased proportion of non-pregnant cows in the younger herd $(57 \%)$ compared with $30 \%$ in the Base Herd. The result is $69 \%$ as many calves weaned in the youngest herd as in the Base Herd (Table 1).

Second, efficiency is more sensitive to changes in age at culling in younger than in older herds. For example, moving from culling at 4.5 years to 5.5 years increases efficiency by 12 units (66 to 78). By contrast, moving from culling at 9.5 years to 10.5 years increases efficiency by only 2 units (98 to 100). In the former case the proportion of non-pregnant cows wintered changes from $57 \%$ to $47 \%$.while in the latter case it moves from $33 \%$ to $30 \%$.

The efficiency of winter feed use is reduced from 100 to 92 if all non-pregnant cows and heifers are wintered but culled before the next joining (Table 1). This policy results in $8 \%$ fewer calves weaned. If only non-pregnant rising 3-year-old heifers are culled before the winter, efficiency is 94 .

Themostefficientoptionis acombinationofpolicies. The effect of single policy changes and the best combination is shown in Table 2 . The best combination of policies is $26 \%$ more efficient than the worst. 
Table 2 Per cent increase in efficiency of single policy changes and the best compared to the worst combination of policies.

\begin{tabular}{lc}
\hline Policy comparison & $\%$ \\
\hline Cull at 10.5 vs 7.5 years & 10 \\
Best vs worst breed of bull & 10 \\
Cull non-pregnant cows and heifers before winter & $\mathbf{8}$ \\
$\quad$ vs after winter & 5 \\
Optimum calving date vs calving 30 days early & 26 \\
Best combination vs worst combination & \\
\hline
\end{tabular}

\section{Discussion}

Our analyses indicate that considerable scope exists for improving the efficiency of winter feed use by the beef breeding herd if a combination of policy options are adopted. The best combination of policies results in an efficiency advantage of $26 \%$ compared with the worst policy examined. Not all available policy options have been examined in this analysis. Some other analyses we havedoneshowthatverylargeimprovementsarepossible if breed of cow, age at first mating and replacement heifer policy are simultaneously altered (McMillan \& McCall, unpublished).

When considered as a single policy change, age at compulsory culling is the policy which offers the greatest scope for changing efficiency. This is particularly so in in herds that cull before 7.5 years since sensitivity is highest in young herds. At the extreme, a very young Angus herd with culling at 4.5 years is only $66 \%$ as efficient as an Angus herd with culling at 10.5 years. Our assumptions of the same performance in 4.5 to 10.5 -year-old cattle appear reasonable in that they are largely supported by international results (Preston \& Willis 1970) as well as New Zealand data (Morris, C.A. pers. comm.). However, published New Zealand data is urgently needed to refine ourmodel. Longevity is clearly animportantconsideration in beef cow efficiency and warrants more attention by the industry than has been the case to date.

Our analyses demonstrate that moderate scope exists for improving the efficiency of winter feed by choosing an appropriate breed of bull. Ranking all of the breeds and strains of bull on only calf birth weight, only calf weaning weight or only calf survival was not useful in predicting final ranking on efficiency. An index which includes calf weaning weight and calf survival is much more informative as a predictor of efficiency. Producers need to bear this in mind when selecting breeds of bull. The most efficient breed of bull improves efficiency by $10 \%$ whereas choosing the most efficient cow breed (Hereford cross Friesian) improves efficiency by $13 \%$ when yearling heifer mating is adopted (McMillan \& McCall 1991). The combination of Hereford $\mathrm{x}$ Friesian cows with yearling heifer mating and French Simmental bulls improves efficiency by $26 \%$ compared to the Base Angus Herd, and then by not wintering $\mathbf{H x F}$ yearling replacements efficiency improves to almost $50 \%$ above the Base Herd (McMillan \& McCall, unpublished), These findings further reinforce the point that combinations of policy changes are required to make large improvements in efficiency in the beef cow herd.

Retaining non-pregnant animals for the winter lowers the efficiency of use of winter feed if they are not joined with the bull in the following season. It makes little difference to efficiency $(<2 \%)$ if only non-pregnant heifers are kept or culled following first mating. Our analyses provide some of the information necessary for a cost/benefit analysis of pregnancy diagnosis and culling before rather than after the winter. The outcome of such an analysis will probably depend on whether non-pregnant animals are subsequently joined with the bull or not.

The efficiency of winter feed use is only influenced to a minor extent by time of calving, provided winter stocking rate is adjusted to reflect the varying winter feed demands of alternative mean calving dates. The optimum time to calve is at the end of the winter i.e., the start of the spring feed flush. Our analysis may not sufficiently penalise herds with an early mean calving date since fertility can be about 5\% lower in early calving herds (Smeaton et al. 1986). Overall, the results indicate that over a range of about 6 weeks the efficiency of winter feed use is largely independent of time of calving. Producers should therefore use other criteria, such as the impact of premiums for larger calves (i.e market factors) or the impact of fewer cows to control the spring feed surpluses (i.e. management factors), to assist them in determining the appropriate time to calve .

It is difficult to gauge the extent to which the beef cow industry could gain from adopting some of the the more efficient policies identified in this analysis. This is because industry statistics on currently adopted policies are not available although some breed statistics are available. Angus, Hereford and Hereford x Angus breeding cows make up about $80 \%$ of the national according to N.Z. Department of Statistics figures for $1986 / 87$ whereas only $3 \%$ of the beef herd are of the more efficient Friesian cross (McMillan \& McCall 1991). Clearly then, considerable scope exists for changing to a more efficient breed of cow. Information on herd age structures, replacement wintering policies, culling policies and breed of bull are urgently required to ensure accurate estimates of the potential benefits to the New Zealand beef cow industry. 


\section{Conclusions}

We have extended the application of our spreadsheet model to determine the relative efficiency of various policies and combinations of policies for the beef breeding herd for using winter feed for weaner calf production. We highlight the point that combinations of policies are needed to maximise efficiency and that some important policies are not examined in this analysis (e.g., breed of cow, age at first mating, and replacement heifer policy). We have identified moderate scope for influencing efficiency with single policy decisions on age at culling, breed of bull and to a lesser extent the fate of non-pregnant cows and heifers. There is an urgent need to obtain information on the current policy practices in beef cow herds so that appropriate research and extension programmes can be devised to improve beef cow efficiency.

\section{REFERENCES}

Baker, R.L.; Carter, A.H.; Morris, C.A.; Johnson, D.L. 1990. Evaluation of eleven cattle breeds for crossbred beef production: performance up to 13 months of age. Animal Production 50: 63-77.

McCall, D.G.; Smeaton, D.C.; Nicoll, G.B.; Dow, B.W. 1987. The productive performance of Hereford X Friesian and Angus cows on N orth Island hill country. Proceedings of the 4th AsianAustralasian Association of Animal Production Societies, p. 353.

McMillan, W.H.: McCall, D.G. 1991. Are yearling heifer mating and more productive beef cow breeds a worthwhile use of winter feed? Proceedings of The New Zealand Society of Animal Production 51: In Press.

Morris, C.A.1982. More beef by using more productive cows and by yearling-heifer mating. Proceedings of the Ruakura Farmers' Conference, pp. 15-19.

Preston, T.R.; Willis, M.B.1970. Beef calf production. Chapter 6, pp. 210-278. In 'Intensive Beef Production' Oxford. Pergamon Press.

Smeaton, D.C.; McCall, D.G.; Clayton, J.B. 1986. Calving date effects on cow productivity. Proceedings of the New Zealand Society of Animal Production 46: 149-152. 